\title{
A NEW METHOD FOR STUDYING BREATHING, WITH OBSERVATIONS UPON NORMAL AND ABNORMAL SUBJECTS
}

\author{
By LESLIE SILVERMAN, ROBERT C. LEE, AND CECIL K. DRINKER, \\ WITH THE COOPERATION OF FRANCIS M. RACKEMANN 1 \\ (From the Harvard School of Public Health and the Nutrition Laboratory, Carnegie Institution \\ of Washington, Boston)
}

(Received for publication April 21, 1944)

\section{METHOD}

The apparatus described in this article is a simple device that will record the changes in the rate of air flow with time during each respiration and without the lag and inertia of other methods. The instrument designed for this purpose consists of a fine platinum wire $200 \mathrm{~mm}$. long and $0.01 \mathrm{~mm}$. (10 microns) in diameter, suspended across the diameter of a $31.6 \mathrm{~mm}$. tube. One end of the wire is attached to a fixed point and the other end to a fine spring. The displacement of the wire when air flows through the instrument is recorded photographically by a moving paper camera. The deflection of the wire is essentially linear with air flow, and the inertia, lag,

- and frequency of vibration do not interfere with respiratory measurements. Unlike other instruments devised for this purpose, this apparatus does not introduce significant resistance to air flow and, therefore, does not affect normal respiration.

The complete measuring apparatus is shown in Figure 1. The inspiratory instrument, with a bell-mouth to prevent turbulent air currents and decrease resistance, is shown at A. The expiratory instrument, with heating bath for preventing condensation in the line, is shown at $B$. The recording wires of these two instruments are shown schematically in the lower part of the figure. The valves for producing directional air flows through the two instruments are shown at C. A large spirometer with slide valves for shifting from the recording instrument to the spirometer for collection of expired air is also shown in Figure 1. A small half mask with minimal dead space is provided with a Heidbrink pneumatic cushion to ensure an air-tight seal to the subject's fuce.

In a recent paper (1), a description was given of the details of construction of this apparatus as adapted to measurements of air flow during inspiration. Since that publication, the device has been modified to record both inspiratory and expiratory air flows. The changes made in the original inspiratory instrument to record expiratory air flows are as follows. To eliminate the effect of the turbulence of the expired air, a fine mesh wire screen (150 mesh Monel wire) is located $5 \mathrm{~mm}$. from the recording wire, and to prevent condensation from expired air in the instrument, a heating bath and a straight section of tubing are inserted in the line before the wire

1 In charge of the Allergy Clinic, Massachusetts General Hospital, Boston. screen. To compensate for the loss in cross sectional area of the tube caused by the wire screen and to reduce the resistance to an amount equal to that of the inspiratory instrument, it was necessary to increase the diameter of the tube of the expiratory instrument from 31.6 to 47.8 mm. Lastly, to prevent extraneous oscillations of the expiratory wire, the lower leg of the channel housing the wire is partially filled with kerosene which acts as a viscous damper. The évasé, a megaphone-shaped outlet shown on the end of the expiratory instrument, also decreases the expiratory resistance. In addition to the above changes, a new valve has been devised, which is indicated on the mask at $C$ in Figure 1. This valve has a resistance of less than $1 \mathrm{~mm}$. of water at an air flow of 100 liters per minute and has a negligible opening pressure. A detailed description of the valve will appear elsewhere. The over-all resistance of the measuring apparatus to either inspiration or expiration is less than $2 \mathrm{~mm}$. of water at 100 liters per minute. This includes the resistance of the spirometer, which is equipped with a well-counterbalanced aluminum bell and a connecting tube of large diameter ( $50.8 \mathrm{~mm}$.).

\section{DESCRIPTION OF TRACINGS}

Typical records for a normal subject (L. S., male, 29 years) are shown in Figure 2. In the upper half of each record is the curve of expiratory air flow and in the lower half, the curve of inspiratory air flow. The time in intervals of one-fifth of a second is indicated by the horizontal line at the top of each record. The curves are read from left to right. The ordinates or vertical movements of the curves on the record represent the volumes of instantaneous air flows at the times indicated by the abscissae or horizontal movements of the time line.

The upper record (I) in Figure 2 represents tracings obtained with a normal subject without any resistance in the line. The curve for normal inspiratory air flow starts at A, has a fairly sharp change to a maximum air flow (as indicated by the steep downward limb of the curve of the inspiratory cycle), then tapers off in flow, and rises 

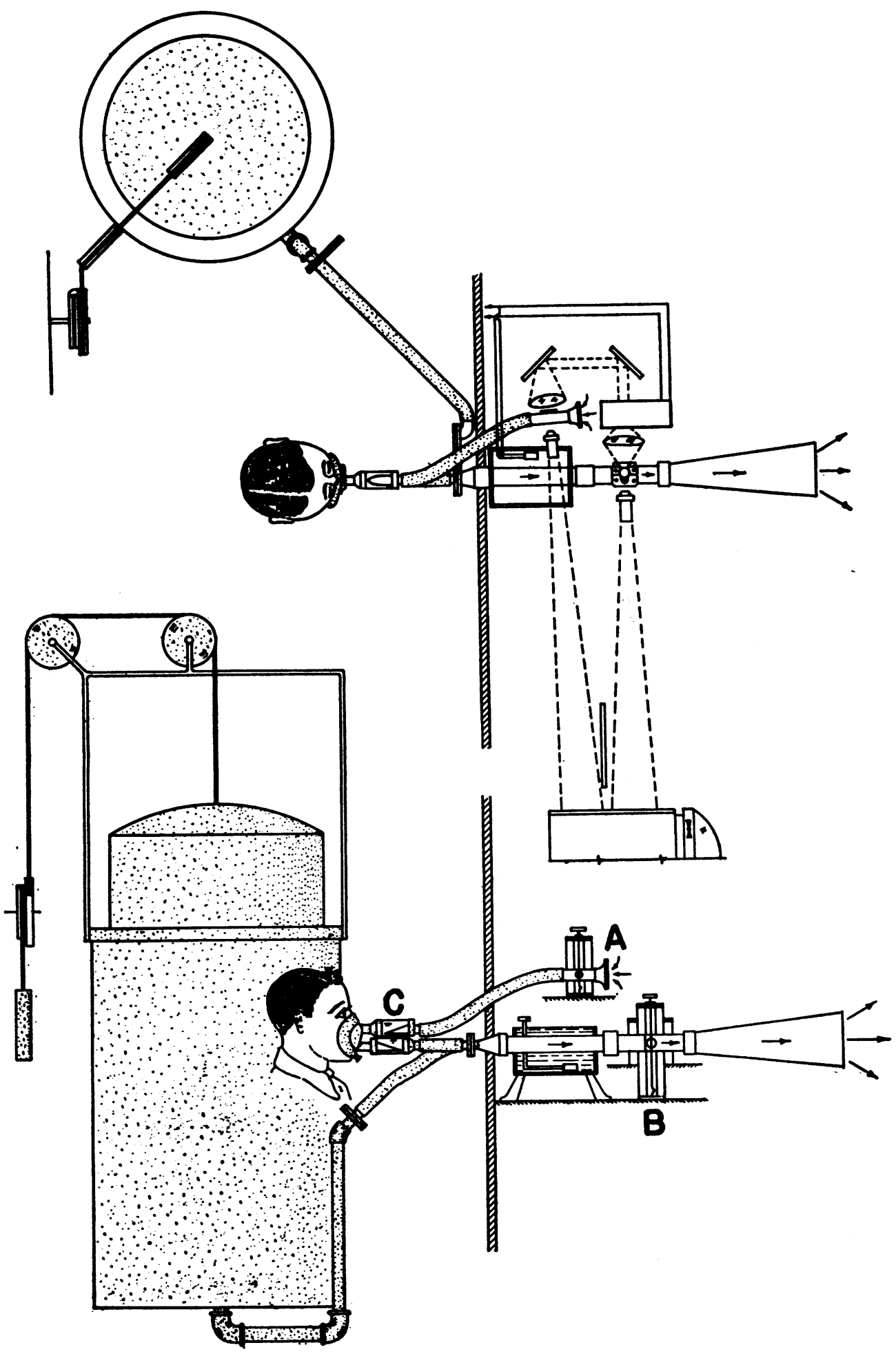

Fig. 1. Diagram of Apparatus for Making a Pneumotachogram and Other Measurements on Breathing Description in text. 


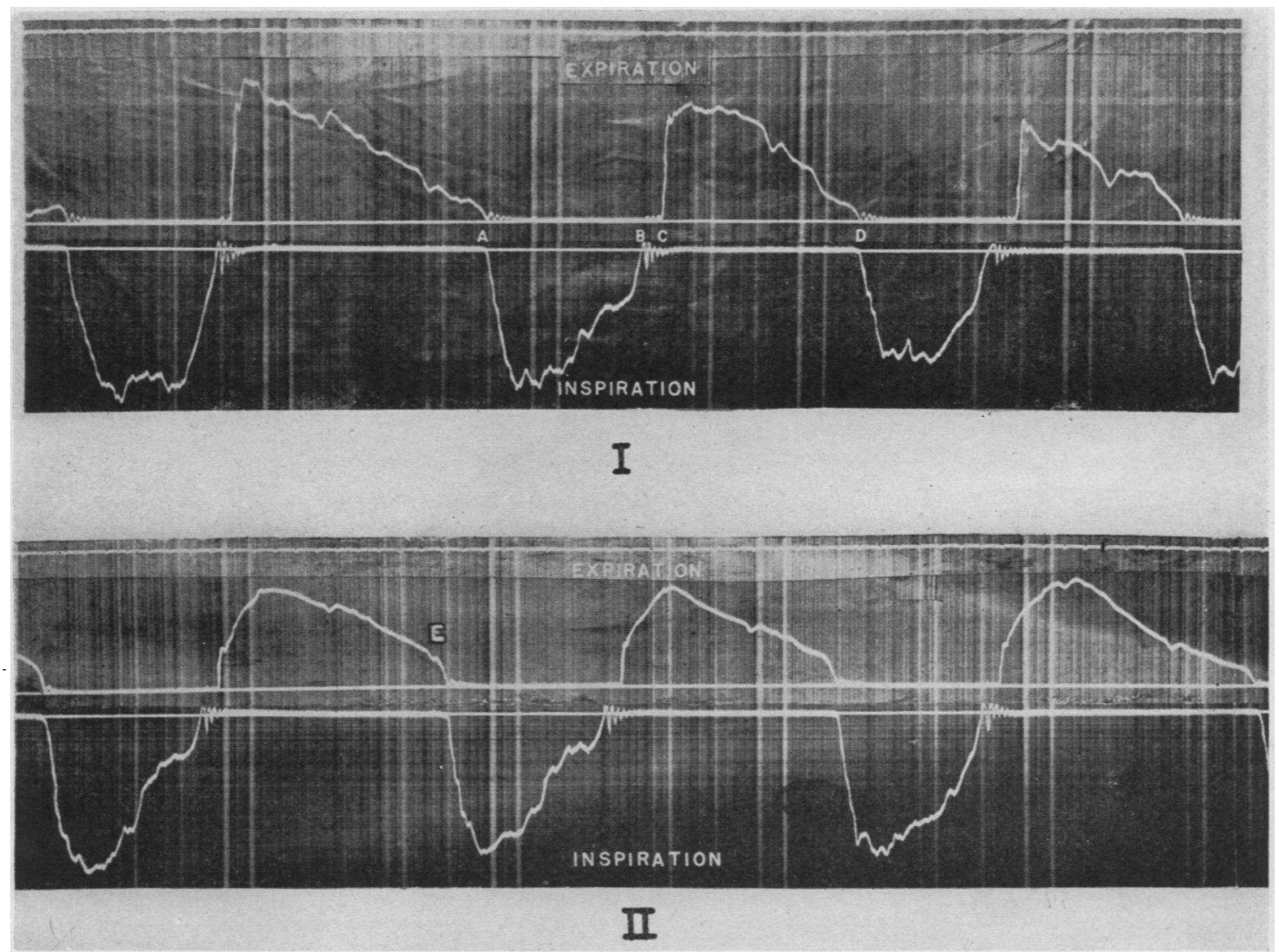

Fig. 2. Typical Tracings Recording the Respiratory Air flow of a Normal 29-year old Man, Without Resistance (UPPer Record, I) and With Resistance (lower Record, II) to Expiration

Inspiration begins at $\mathrm{A}$ and continues to $\mathrm{B}$. The maximum rate of inspiratory air movement occurs abruptly, as indicated by the downward limb of the curve, and the inspiratory flow falls off to zero during the gradual upward limb of the curve ending at B. Expiration begins at $\mathrm{C}$ with a rapid movement of air, and the flow falls off to zero at $\mathrm{D}$. In the lower record, the same subject breathed against resistance to expiration of $0.9 \mathrm{~mm}$. of water per liter of air flow per minute. In all records, the areas bounded by the zero line and an inspiratory curve or the zero line and an expiratory curve from start to end represent the volume of air per breath or tidal volume.

towards the base-line until it reaches zero flow, when it crosses the horizontal line for zero flow at B. The curve for normal expiratory air flow begins at $\mathrm{C}$, its rising limb rapidly reaches a height indicating maximum expiratory flow, and the curve then falls off gradually to zero flow at D. These tracings should not be confused with the ordinary spirogram, in which upward movement represents inspiration and downward movement expiration. Each pair of curves in these records is a complete record of the pattern of air flow during each phase of respiration. The area bounded by the zero line and the curve of inspiration between $\mathrm{A}$ and $\mathrm{B}$ or the area bounded by the zero line and the curve of expiration between $\mathrm{C}$ and $\mathrm{D}$ represents the volume of air per breath or tidal volume. By adjustment of the tension of the wires, both of the recording wires are set to have approximately the same sensitivity, at a constant air flow, which is provided by a calibrated rotameter or flow meter. The slight differences between the areas bounded by the inspiratory and the expiratory curves and the zero lines in Figure 2 and in succeeding figures are ascribable to slight differences in the adjustments of sensitivity of the inspiratory and the expiratory instruments. The wires are calibrated individually at a constant air flow, for critical analysis of the tracings. 
The individual characteristics of breathing resulting from jerky muscular movements cause the variations in contour of the curves throughout the tracing. In the background, on the tracing lines, the free vibrations of the measuring wire at a much higher frequency of air flow are apparent.

The lower record (II) in Figure 2 was obtained on the same subject when a resistance had been

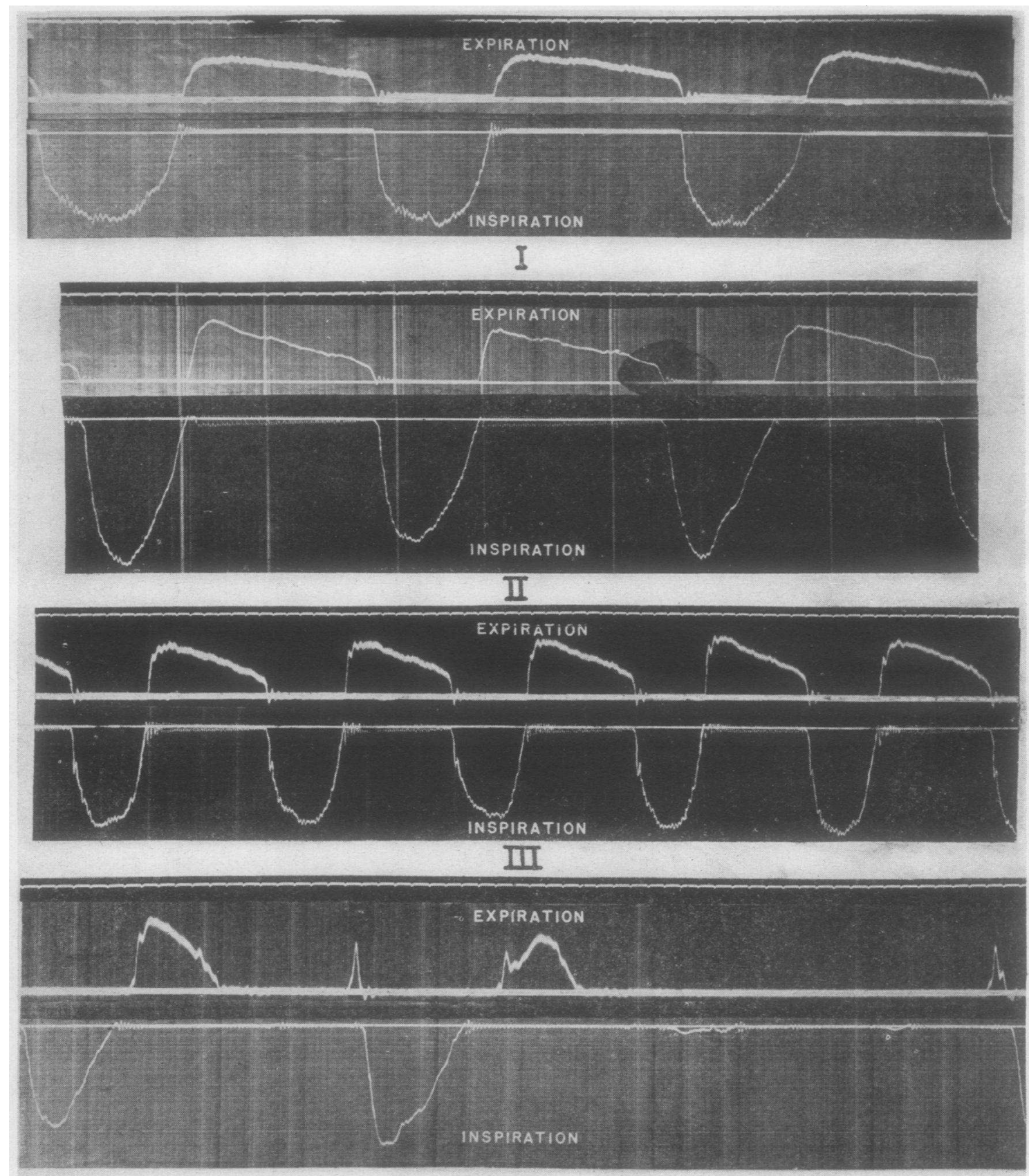

\section{IV}

Fig. 3. Pneumotachograms from 4 Patients Under Observation in the Allergy Clinic of the Massachusetts General Hospital in the Service of Dr. Francis M. Rackemann

Descriptions in text. 
inserted in the expiratory line. This resistance was made by a glass filter cloth, which was held between two flanged funnels. The funnels were heated to prevent any adsorption of moisture and change of resistance. The resistance of this filter cloth arrangement increases linearly with increasing air flow and has a value of $0.9 \mathrm{~mm}$. of water per liter of air flow per minute. With this amount of expiratory resistance, the flow of expiratory air is maintained at a measurable volume because of the forced expiration until the end of the expiratory phase or effort, when the flow drops off suddenly. In this type of expiration, the gradual approach to zero flow is absent, the expiratory tracing is much smoother and indicates a sudden fall of flow at the end of expiration rather than the gradual return to zero flow shown by the tracing for the same subject without the resistance in line.

The viscous damping of the expiratory instrument produces a very slight lag in the return of the curves of expiratory air flow to the zero line, if this occurs suddenly, that is, in less than 0.04 second.

\section{OBSERVATIONS UPON PATIENTS}

As experience with the method accumulated and the sensitivity of the new spirograms (pneumotachograms) for portraying characteristics of breathing entirely unrecognizable in the usual curves became apparent, it was obviously worth while to see what the method would show when used for examination of patients with abnormal breathing. Accordingly, Dr. Francis M. Rackemann was asked to send 8 patients to the laboratory. These individuals had long records of observation in the wards and in the Allergy Clinic of the Massachusetts General Hospital. All were equal to limited physical activities, and no one was in the least annoyed by the procedures involved in making the records. Indeed, the cooperation of subjects in this type of test is less exacting than that required in determination of the basal metabolism. The subject sits comfortably in an armchair. The face mask with valves attached is applied, and natural breathing continues. The recording apparatus is on the other side of a partition, and the patient has no knowledge of when records are being made or in what ways the act of breathing is being hindered or assisted, if such changes are used to display or magnify peculiarities in respiration.

The compelling nature of other work has prevented us from the extensive clinical studies that the method merits. Our purpose in this paper is to show some of the results obtained with the new technic and to make this technic available for clinical employment by those interested in the problems of abnormal breathing. Accordingly, in Figures 3 and 4 are presented single records

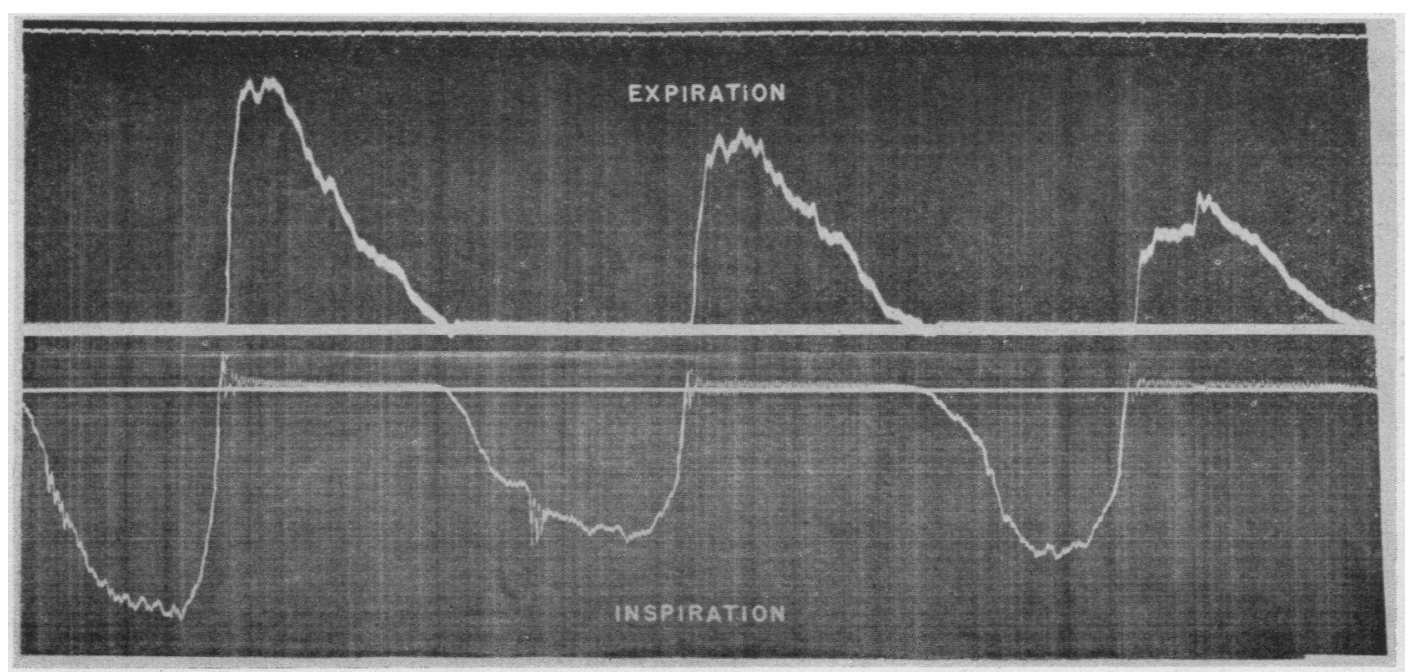

Fig. 4. Pneumotachogram from a Fifth Patiext from the Allergy Clinic

Description in text. 
TABLE I

Results of pneumotachographic observations on a normal man and on patients with respiratory abnormalities

\begin{tabular}{|c|c|c|c|c|c|}
\hline \multirow{2}{*}{ Condition and subject } & \multirow{2}{*}{$\begin{array}{l}\text { Respiration } \\
\text { rate }\end{array}$} & \multirow{2}{*}{$\begin{array}{l}\text { Minute } \\
\text { volume }\end{array}$} & \multirow{2}{*}{$\begin{array}{l}\text { Respiratory } \\
\text { quotient }\end{array}$} & \multicolumn{2}{|c|}{ Mean maximum air flow } \\
\hline & & & & Inspiration & Expiration \\
\hline $\begin{array}{l}\text { Normal (L. S.) } \\
\text { No resistance to expiration } \\
\text { Resistance to expiration }\end{array}$ & $\begin{array}{c}\text { per minute } \\
\\
15.8 \\
15.3\end{array}$ & $\begin{array}{r}\text { liters } \\
8.3 \\
7.7\end{array}$ & $\begin{array}{l}0.77 \\
0.79\end{array}$ & $\begin{array}{l}25 \\
31\end{array}$ & $\begin{array}{l}23 \\
20\end{array}$ \\
\hline $\begin{array}{l}\text { Patients with respiratory abnormalities } \\
\text { J.P. } \\
\text { W. E. D. } \\
\text { W. F. L. } \\
\text { J. M. } \\
\text { S. M. }\end{array}$ & $\begin{array}{l}15.8 \\
16.7 \\
22.0 \\
10.2 \\
12.0\end{array}$ & $\begin{array}{r}11.6 \\
9.3 \\
9.2 \\
5.4 \\
7.9\end{array}$ & $\begin{array}{l}0.97 \\
0.91 \\
0.88 \\
0.80 \\
0.75\end{array}$ & $\begin{array}{l}38 \\
53 \\
37 \\
40 \\
51\end{array}$ & $\begin{array}{l}25 \\
28 \\
27 \\
30 \\
51\end{array}$ \\
\hline
\end{tabular}

from 5 patients, and in Table I are summarized the results of the observations on these patients and likewise those on the normal subject previously mentioned.

Patient 1, J. P., male, 46 years (pneumotachogram I, Figure 3). Since the age of 38 , the patient has had asthma. His symptoms are related to exertion. In pneumotachogram I, inspiration and expiration are smooth and regular in character. Expiratory movement of air is in the nature of a slow push and ceases entirely a little before the cycle of expiration is finished. When expiration ceases, the flow drops quickly to zero, as was the case in the normal subject when resistance was placed in the expiratory line (Figure 2, lower half, II). The rounded character of the inspiratory curve indicates some degree of resistance to inspiration.

Patient 2, W. E. D., male 50 years (pneumotachogram $I I$, Figure 3). At the age of 40 , the patient began to have dyspnea on exertion, and now is a typical instance of emphysema accompanied by asthmatic attacks. The similarity of his record (pneumotachogram II) to that of the first patient requires no comment.

Patient 3, W. F. L., male, 19 years (pneumotachogram III, Figure 3). The patient has had asthma for 17 years. The tracing is again characteristic of breathing obstructed at expiration and somewhat so at inspiration.

Patient 4, J. M., male, 63 years (pneumotachogram $I V$, Figure 3). Asthma began at the age of 45 in isolated attacks but was not bad until his 50th year, when he was admitted to the hospital for treatment. This is an instance of extreme emphysema and asthma. When pneumotachogram IV was obtained, the patient was breathing irregularly and was obviously ill but did not object to wearing the face mask and cooperated well in the observation. His breathing consisted of complete respiratory cycles with trifling inspiratory and expiratory efforts in between. Most of these would not be noted by any other means of observation. The failure of this patient to provide the type of expiratory curve characteristic of the previous patients is apparently ascribable to loss of ability to continue to force air out of the lungs. However, there is a final expiratory effort or blow just before inspiration begins, which causes the small expiratory "spike" before the inspiratory curve.

Patient 5, S. M., male, 44 years (pneumotachogram in Figure 4). This man has had hay fever since the age of $30 . \mathrm{He}$ is a pessimistic individual who complains of more symptoms than seem to be present. The curves in Figure 4 are of unequal extent but are repetitive in configuration. The expiratory curve does not have the contour characteristic of the curves of the asthmatic patients mentioned above. However, the inspiratory phase indicates that some inspiratory resistance is present. The inspiratory curves are similar to those of patient 3 .

The data in Table I were obtained at the time of photographing the records shown in Figures 2, 3, and 4. The maximum flows and respiration rates were calculated directly from the pneumotachograms.

\section{DISCUSSION}

In addition to the features of the pneumotachograms discussed above, another point of interest noted thus far is the tendency of the individual to maintain a uniform configuration of inspiratory and expiratory curves. This is one of the characteristics of the pneumotachogram which should make the technic profitable in following the condition of patients during the progress of or recovery from a respiratory disease, for the repeated examination of young men in training, and for the examination of children during growth. The absolute objectivity of the method and the ease with which the subject is kept unconscious of his moment of participation in the test may be of use in psychologic and psychiatric studies. The apparatus can be constructed by a good mechanic furnished with the 
directions available in the paper by Lee and Silverman (1).

\section{SUM MARY}

A new pneumotachographic device is described for making a graphic record of the velocity of air movement during inspiration and expiration. The inspiratory and the expiratory air currents cause the deflections of fine wires, deflections that are recorded photographically by a moving paper camera. Typical illustrations of the resulting curves are presented, showing the results on one normal individual and on 5 patients with respiratory difficulties. The total minute volume and the instantaneous air flow can be obtained from the records made by the instrument.

\section{BIBLIOGRAPHY}

1. Lee, R. C., and Silverman, L., An apparatus for measuring air flow during inspiration. Rev. Scient. Instruments, 1943, 14, 174. 